\title{
Introduction: Rethinking Fundamentalism in a Post-Secular Age
}

\author{
Aakash Singh ${ }^{1}$ \\ Received: 27 April 2015 / Accepted: 27 April 2015 / \\ Published online: 16 May 2015 \\ (C) Springer Science+Business Media Dordrecht 2015
}

The collection of papers presented in this issue of Philosophia represent a sample of writings arising from an early stage of the newly emerging international and multidisciplinary research project called "Reopening the Fundamentalism Project." The project is spearheaded by the International Research Network for Religion and Democracy (IRNRD). It is an "early stage" because within the overarching task of reopening such a vast project, we begin by carefully rethinking it. And that is what the papers in this collection do - they force us, in various ways, to rethink or reconsider the dominant views, both academic and quotidian, about what fundamentalism is, means, and does, and the environment, both academic and quotidian, wherein this all happens.

With very few exceptions, throughout the 1960s and 1970s, there was academic consensus - including philosophers, social scientists, and grudgingly even theologians - that modernity inevitably brought secularization. In the late 1970s, however, the new visibility or re-emergence of fundamentalist movements in mainstream societies across the world led to gradual erosion of that consensus. The rise of the American "Moral Majority," the Islamic Revolution in Iran, the new patterns of post-colonial immigration and the public increases of Muslim agitation in Europe, along with other manifestations of religion in the public sphere, began to convince philosophers, sociologists, political theorists, theologians, and other scholars that religious identity was not on the brink of disappearance, but on the contrary, was showing indications of both growth and push back. Within the context of this slow shift of academic awareness, the American Academy of Arts and Sciences commissioned the original "Fundamentalism Project." That project hypothesized that fundamentalism could be taken as a "family resemblance" concept, identifying and at times even linking the genesis and evolution of fundamentalist developments across numerous religious traditions around the world. The premise was simply this: manifold religious movements emerging in different cultures across the globe exhibited discernible, common traits, and thus could be collectively subsumed under the category "fundamentalism." Though controversial,

Aakash Singh

aakashsinghrathore@yahoo.com

1 LUISS University, Rome, Italy 
the approach resulted in the publication of five path-breaking "Fundamentalist Project" volumes between 1991 and 1995 .

The original Fundamentalism Project has been closed for two decades now. But developments since its closure have kept apace with or even outstripped those of the late 1970s and 1980s that led to pursuing it in the first place. Obviously, the postSeptember 11 environment has pushed to the forefront ideas about religious violence and civilizational clashes. Along with the simmering cauldron of tension surrounding the issues of Islam in North America and Europe there is also the seemingly irrepressible eruption of communal violence in India, some of the worst of which has been supported by BJP party members who have recently taken the reigns of Indian government. Groups of politically engaged activist monks in Buddhist countries are yet another example of recent developments of strong religion's increasing salience in South and South East Asia. The violence committed by the Boko Haram movement, the conflicts in Libya, and the controversial post-revolutionary situation in Egypt mark some of the flash points in the African continent. The developments in the MiddleEast - the recent war between Israel and Hamas, the rise of ISIS in Iraq and Syria-establish that fundamentalism and radicalization will continue as major challenges in the near future. Noteworthy, the continuous involvement of North American and European youth in the Middle East, along with the presence of ISIS troops in Indian Kashmir, shows that these challenges bear direct and destabilizing trans-national consequences, which need to be addressed from a multi-national and multi-disciplinary perspective.

The original Fundamentalism Project had found that "[f]undamentalisms arise or come to prominence in times of crisis, actual or perceived," and linked the understanding of fundamentalism to the preservation of a distinct identity. These are no doubt relevant factors, but as apparent from the articles collected in this issue of Philosophia, the process of rethinking the Fundamentalism Project takes a different point of departure. The authors of these papers seek to analyze the re-emergence and new forms of religious fundamentalism, both the radicalized as well as the a-political, along with the rise of related forms of political extremism today. The broader ambition of Reopening the Fundamentalism Project is informed by Torkel Brekke's hypothesis that the key factor in understanding fundamentalisms and various forms of radicalization lies in the erosion of traditional forms of authority (see especially Péter Losonczi's paper in this issue). The project aims to unveil those trends, some distinctive, but most others interrelated, that have generated various forms of fundamentalist and extremist reactions to modern developments the world over (see especially Mathias Riedl and Dave True's papers in this issue).

In this respect it is crucial to rethink the diverse forms of fundamentalism and radicalism that have emerged or re-emerged after the conclusion of the original Fundamentalism Project. For example, think of the rise of the new extreme right parties in Europe, themselves creating a heterogeneous group whose nexus with international fundamentalist groups is a complex issue in itself (see Theo De Wit's paper in this issue).

Coming back round to the early academic consensus regarding secularization as the inevitable byproduct of modernity, rethinking fundamentalism within the ambit of the now-increasing awareness of a "post-secular condition" permits us to analyze the recent developments in a new light. For example, we may now see more clearly that the 
activities and various kinds of tropes of fundamentalist discourse have not been merely reactive to modernity (such as scholars like Habermas himself have claimed); rather, the numerous fundamentalist movements have proactively appropriated techniques and strategies that belong to modernity (see especially Péter Losonczi, Dave True, and Mathias Riedl's papers in this issue). Among the upshots of this realization, this means, for example, that while rethinking fundamentalism today we cannot neglect to consider the role of technology, communication, social media and other factors that have substantially contributed to the formation of the late modern and contemporary situation.

The dynamics of the reactive and proactive elements of fundamentalism today; the variety of new spaces that fundamentalist mentalities, discourses, activities now occupy; and the outright omnipresence of the phenomenon the world over demand the rethinking of fundamentalism in creative ways. Methodologically, this means crisscrossing inter-contextuality with multi-disciplinarity. Inter-contextuality refers to, on the one hand, consideration and sensitivity to the uniqueness of different contexts (geographic, cultural and political regions), while on the other hand, recognizing the constant interplay and mutual influence of these regions in the wake of globalization (even taking the latter term simply as representing the rapid and increasingly unhindered movement of, say, goods, services, persons, capital, technologies, visual transmissions, art, music, ideas, ideologies, conspiracies, infections, and arms right across the globe). Even assuming the overarching hypothesis on the loss of traditional forms of authority, while conducting research on a global scale, inter-contextualism amounts to abandoning any kind of master narrative; at the same time, eschewing methodological tribalism. Multi-disciplinarity is essential insofar as the phenomena we treat are complex in their historical development and internal constitution. To avoid a reductionist fallacy and simplifications multiple disciplinary vantage points on religion, culture, and politics must be synthesized. Even the papers in the present journal issue canvas approaches from philosophy, sociology, political theory, history, religious studies and theology. The wider reopening project supplements these disciplines also by gender studies, area studies, cultural anthropology, IT and communication theory, media studies, art history, legal studies, ecology, economics, and other relevant established and emerging domains of scholarship.

Charlie Cooper and Usama Hasan's paper "The Balanced Nation: Islam and the challenges of extremism, fundamentalism, Islamism and jihadism" is a superlative example of the kind of rethinking being proposed. The paper offers a working definition of "fundamentalism" within the purview of Islam as a global religion (i.e., fundamentalism as "the reading of scripture without reference to normative religious and historical context"). Cooper and Hasan seek to carefully disentangle the concept of "fundamentalism" from the terms with which it is routinely conflated and confused. Whether on the streets, in the news media, or even in academic scholarship, we find these "befuddling, polymorphous nomenclatures that straddle the middle ground between politics and religion." As the authors very rightly suggest, within the context of globalization, "of unprecedented cultural, social and political exchanges across the international community - it is absolutely imperative that analysts and decision-makers alike can discern the fundamental differences between disparate sociopolitical phenomena like extremism, fundamentalism, Islamism and jihadism." 
Cooper and Hasan deliver just as promised. Through painstaking reexamination and analysis, they delineate the horizon of the four selected terms, and envision them within decreasing concentric circles of meaning, of more and more narrow species specificity in a genus-species relationships. Extremism is the widest, and can include secular movements as well as religious ones. Religious extremism is not necessarily political, nor necessarily fundamentalist. Fundamentalism, then, is not so much a behavioral category as a doctrinal one. As doctrinal, the concept of fundamentalism may be regarded as universalizable, applicable to all religions where the importance of scripture and dogmatic foundations assumes priority over all else, including historical context. Fundamentalism, thus conceived, is a species of extremism - religious extremism. But obviously, and just think of the classic example of the Amish, fundamentalism can be quietist and isolationist just as well as politicized and interventionist. It is the latter that characterizes the Islamist. So the Islamist is a species of fundamentalist, an overpoliticized and interventionist one. And falling within the latter category, deploying violence and condoning terrorism, is the jihadist.

In his paper, "Terrorism as 'Apocalyptic Violence': On the Meaning, and Validity of a New Analytical Category," Matthias Riedl treats of another term firmly nestled within the current vocabulary spiraling around the discourse of fundamentalism: "apocalyptic violence." Pursuing the orientation of the Reopening Project, Riedl - a historian specializing in the politics and religious history of the medieval world - brilliantly analyzes apocalyptic violence, viewing it as a peculiarly modern phenomenon. Conceptually distinguishing it from its pre-modern historical antecedents, and drawing on several concrete cases, ranging from the USA, to Scandinavia, to Japan, the author shows that apocalyptic violence presupposes decidedly modern socio-economic and intellectual conditions that ground the shift from quietist determinism to revolutionary activism.

Péter Losonczi also reflects upon these same themes - modernity and fundamentalism, secularism and changing currents in the history of mentalities - but he approaches them from a philosophical perspective informed by an intersection of social theory and hermeneutics. In his paper, "Modernity, Postsecularism, Fundamentalism," Losonczi undertakes engagement with the work of Juergen Habermas, reread in the light of recent literature specifically on fundamentalism by Torkel Brekke and new ways of understanding certain developments within modernity by Adam Seligman.

A paradigmatic example of rethinking about a paradigmatic context is found in Dave True's work on protestant fundamentalism. In his captivating paper, "The Triumph of the Personal: American Fundamentalism Comes of Age," True revisits the most classical and archetypal case of fundamentalism by way of an analysis of the situation today. What he finds is that protestant fundamentalism has become a secularized American political theology. "American fundamentalism," in contrast and distinction from "Christian" or "protestant" fundamentalism, is a particular way of thinking about the nation-state. To reach these conclusions, True carefully reads and reflects upon the work of William E. Connolly - but in the end, sublates this work, picking up certain elements of Connolly's thought, but rejecting his overall orientation, within which there is a tendency to present American fundamentalists as alien or fringe. True believes that this is not borne out by the empirical evidence. As the author concludes: "In the American context, secularism is only part of the story. Public religions are alive and well...." 
And what, then, of Europe? The papers collected here have crossed borders, fused disciplines, and also gone back to basics - American fundamentalism, as the historical original, and Islamic fundamentalism, as the present bogeyman. The theologian and philosopher Theo De Wit turns our attention back to the heart of secular modernity and the home of enlightenment rationalism. In his paper, "Between indifference and the regimes of truth. An essay on fundamentalism, tolerance and hypocrisy," De Wit spirals around the touchstone issues, the peculiar social, cultural, political, aesthetic, and theological conditions, that can allow us to understand the disruptive transformations that northern Europe, and especially the Netherlands, are undergoing today, catalyzed by rapid demographic changes. The rise of the right-wing parties, the murder of Dutch film director and hard-line critic of Islam, Theo van Gogh, the Danish cartoon controversies - De Wit sheds light on these phenomena by way of intersecting a reading of Isaac Bashevis Singer's novel The Penitent, against the political philosophy of Michael Walzer, and through the lens of Paul Ricoeur and Robert Spaemann.

By insightful, wide ranging exercises in rethinking various aspects of the original Fundamentalism Project, these exceptional studies collected together in this issue of Philosophia serve to establish manifestly the need for Reopening the Fundamentalism Project. This program of the IRNRD brings together scholars from around the world working within diverse, relevant disciplines to discuss theoretical, conceptual, and practical problems concerning the concept of fundamentalism and the future that lays before it. The aim is not to demonstrate consensus on the nature, scope, or future of fundamentalism, but predominantly to illustrate its profound significance, and thereby, the urgency of the need to approach it systematically, comprehensively, and with all the rigor available to contemporary scholarship. 